Research Group: Behavioral and Experimental Economics

November, 2009

\title{
How to Adapt to Changing Markets: Experience and Personality in a Repeated Investment Game
}

\author{
ASTRID HOPFENSITZ AND TANJA WRANIK
}




\title{
HOW TO ADAPT TO CHANGING MARKETS:
}

\section{EXPERIENCE AND PERSONALITY In A REPEATED INVESTMENT GAME}

\author{
Astrid Hopfensitz \\ Toulouse School of Economics \\ University of Toulouse 1 \\ France \\ Astrid.Hopfensitz@univ-tlse1.fr
}

\author{
Tanja Wranik \\ Department of Psychology \\ University of Geneva \\ Switzerland \\ Tanja.Wranik@unige.ch
}

NOVEMBER 2009

\begin{abstract}
:
Investment behavior is traditionally investigated with the assumption that it is on average advantageous to invest. However, this may not always be the case. In this paper, we experimentally studied investment choices made by students and financial professionals facing alternately an advantageous and disadvantageous environment in a multi-round investment game. Expected returns from investment in the advantageous environment were higher than a safe alternative, while expected returns were lower in the disadvantageous environment.

We investigate how experience and personality are related to choices. Investment behavior does not differ dependent on expected returns and professionals do not significantly differ from students. Personality predicts behavior and in particular we observe that openness to experience was an asset in unfavorable markets, leading to reduced risk taking.
\end{abstract}

JEL: D14, D53, D81, G11, C91, C93

\footnotetext{
* We would like to thank Michel Odehnal and Stephane Peysson for help with programming the experimental interface and Marina Bianchi-Galanti and Cristina Rivera for the excellent help running the experiments. Financial support through a NETSPAR research grant awarded to Astrid Hopfensitz and Tanja Wranik is gratefully acknowledged. This is an interdisciplinary project between economics and psychology, and both authors contributed equally to the research.
} 


\section{Introduction}

A large body of research in economics and finance has focused on understanding risk taking behaviors in financial markets. Much of this research has been motivated by the observation that stocks have significantly higher average long term returns that bonds (Mehra and Prescott, 1985) ${ }^{1}$ and that investment in bonds is higher than reasonable levels of risk aversion would predict. Thus, a major research question is to understand why investment in stocks is not higher. Accordingly, most experimental studies in this area have been constructed such that investment decisions are made between "risky" and "safe" projects, where returns from the risky project(s) are on average higher than returns from the safe project(s).

In real life, the observation that returns from stocks are higher than returns from bonds are long term averages, and obviously investment in stocks might be more or less advantageous during certain periods compared to others. Unfortunately, there has so far been little research to examine how investors react during unfavorable or changing market periods. Since generally people are observed to be risk averse (Holt and Laury, 2002) almost no investment would be predicted in an environment where expected returns from a risky option are lower than from a safe option. And consequently unfavorable investment tasks have so far been little studied by economists. Meanwhile psychologists have developed the "Iowa Gambling Task", which represents a gambling situation where a risky option gives high returns but has a lower expected value than a safe option. This task has been used with emotionally impaired brain patients to confirm that lack of emotional competence can lead to long term disadvantageous investment decisions (Bechara et al., 1997) ${ }^{2}$. Normal controls are able to distinguish between the two tasks. While this indicates that people are able to identify the situation giving them higher returns in expected terms it gives no indication of how people react if their only option is either an advantageous or disadvantageous investment option. The aim of our study is to understand how investor reactions and behaviors differ in advantageous and disadvantageous market conditions and how these are related to both experience and personality.

\footnotetext{
${ }^{1}$ Specifically: "Over the ninety-year period 1889-1978 the average real annual yield on the Standard and Poor 500 Index was seven percent, while the average yield on short-term debt was less than one percent".

${ }^{2}$ However, such patients also invest more than controls in situations where investment is advantageous (Shiv et al, 2005a/2005b). Thus a lack of emotions generally leads to more risk taking and gambling, independent of whether the participant is in a good or a bad market condition.
} 

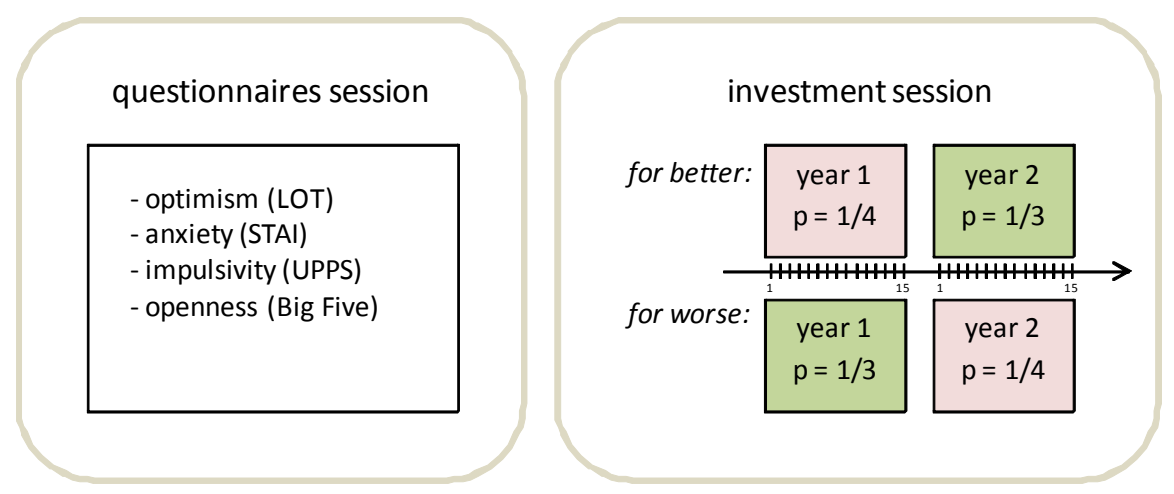

Figure 1: Sessions of the experiment. Note that for students the questionnaire session took place about one week before the investment session. For professionals the questionnaire session followed immediately the investment session.

We present results from an economic experiment investigating behaviors when market conditions change. Specifically, we compare behaviors of naive investors (i.e. students) with experienced investors (i.e. professionals of the financial industry). Previous research has shown that professionals often show the same biases as naive investors, and also that professionals can sometimes have stronger biases than non-professionals (Haigh and List, 2005). Clearly, there are many reasons (training, experience, etc.) why professionals might react differently from students (e.g. Burns, 1985, Potters and van Winden, 2000). Another important reason might be selfselection of people with specific personality profiles into certain professions. Such self selection has been observed for entrepreneurs (Brandstaetter, 1997) and financial traders (Lo et al., 2005). When comparing behavior between experienced and inexperienced investors, we therefore also took into account their specific personality profile. Consequently, we will explore the relationship between experience, personality, and investment behavior in two market conditions: one of which is 'advantageous' the other 'disadvantageous'.

\section{Methods and Predictions}

In this paper, we present an experiment in which students and finance professionals participated in a repeated investment game. The game consisted of two years of 15 rounds each. In one year investment was advantageous, and in the second year investment was disadvantageous. In addition to investment behavior, we also report a number of personality traits that were measured in a separate session (see Figure 1). 
The investment task is based on the type of repeated investment task generally used to study myopic loss aversion (Gneezy and Potters, 1997; Thaler et al., 1997; Bellmare et al., 2005). In this task, participants repeatedly make decisions concerning the allocation of points into two projects. In our case, participants received 100 points each period, which they could use for investment. Note that previous earnings could not be used for investment, and that therefore the available budget stayed constant throughout the task. Participants could chose to invest their budget into a "safe" project, in which each point invested was simply added to the cumulative earnings, or a "risky" project. The risky project was a project in which the participant had a probability $p$ of receiving the invested amount multiplied by 2.5 plus the initial investment, and a probability (1-p) that the amount invested into the project during the round would be lost. In past studies the probability of winning was set to $p=1 / 3$, which meant that investment was on average advantageous $(\mathrm{EV}=1.17)$ since it was larger than returns from the safe project $(\mathrm{EV}=1)$.

In our study, participants had to make investment decisions in two different market conditions. The risky option in the first market had a probability of winning of $p=1 / 3$, and in the second market a probability of winning of $p=1 / 4$. We will call the year with a probability of $p=1 / 3$ the "good year" since investment was on average advantageous $(\mathrm{EV}=1.17)$. In contrast, investment in the year with $\mathrm{p}=1 / 4$ was in expected terms disadvantageous $(\mathrm{EV}=0.875)$, and we will refer to it as a "bad year". The first treatment variable was the order in which the participant entered into the good versus the bad year (see Figure 1: 'for better' and 'for worse').

To control for personality differences, participants also filled out a number of standardized personality scales during a second session. Variables of interest included trait optimism, trait anxiety, impulsivity, and openness to experience. Trait optimism was measured with the 10-item LOT-R (Carver and Scheier, 2001), which includes four filler items, three positively-worded items, and three reverse-coded items. Respondents indicate their degree of agreement with statements such as, "In uncertain times, I usually expect the best," using a five-point response scale ranging from "strongly disagree" to "strongly agree." Negatively-worded items are reversed, and a single score is obtained indicating the degree of optimism. Anxiety was measured with the 20-item STAI-Trait questionnaire (Spielberger, 1972). This instrument assesses the relative frequency of general nervousness or anxiousness in different contexts, and participants 
rate the relatively frequency with which they engage in the described behavior on a four point scale $(1=$ almost never; 4 = almost always). General personality was measured using the Big Five Personality Inventory (BFI) developed by John and Srivastava (1999). The "Big Five" are broad categories of personality traits thought to be the most parsimonious in describing interindividual variation in behavioral propensities. The BFI includes items pertaining to Extraversion (e.g., talkative, energetic), Agreeableness (e.g., kind, warm), Conscientiousness (e.g., efficient, organized), Neuroticism (e.g., moody, touchy), and Openness to Experience (e.g., imaginative, complex). The 44-items are presented as a series of affirmations, and participants are asked to indicate the extent to which they agree or disagree with them, using a 1 (disagree strongly) to 5 (agree strongly) response format. For this study we only examined Openness to Experience. Finally, we measured impulsivity using the UPPS Impulsive Behavior scale (Whiteside and Lynam, 2001). This instrument measures four distinct traits related to impulsivity: (a) lack of premeditation; (b) urgency; (c) sensation-seeking; and (d) lack of perseverance. The 45 items are presented as a series of affirmations, and participants are asked to indicate the extent to which they agree or disagree with them, using a 1 (agree strongly) to 4 (disagree strongly) response format.

\subsection{Procedures}

The experiment was conducted in Spring 2009 at the University of Geneva, Switzerland. Student participants were recruited by announcements promising a monetary reward and were asked to sign up for two one-hour sessions. The first was a questionnaire session; the second was the experimental session in which participants completed the investment task. Professionals were invited by their human resources (HR) manager per e-mail (see Appendix B). For them, monetary rewards were not explicitly mentioned in the invitation, and they accepted in order to help the research of the HR manager who invited them. For practical reasons, professionals were only required to come to the University laboratory once, and to complete both sessions on the same day. To avoid carry over effects from the personality questionnaires, professionals first participated in the experimental session and then filled out the personality questionnaires. Both students and professionals were paid their earnings from the investment task at the end. Average earnings for students were around 31.3 CHF (approx. $27 \mathrm{USD}$ ) and for professionals 58.9 CHF 
(approx. 52 USD). In total, 31 professionals (22 men, 9 women; mean age 43.9, std. dev. 9.25) and 46 students ( 25 men, 21 women; mean age 27.0, std. dev. 8.02) participated in the study.

Professionals came from a small private bank in Switzerland. The bank employs around 100 people in four different locations in Switzerland. The areas of expertise are: private banking, institutional asset management, fund administration and services for independent asset managers. The aim of the bank is to "apply advanced financial techniques to client service, to protect their assets from the hazards of speculation, and to ensure regular returns over the medium and long term". The size of the bank requires small teams to work in close liaison with the asset managers. The proximity also allows them to share information with respect to financial markets and sectors of particular interest. The 31 professionals participating in the experiment came from various sites of the bank. They also represent a variety of nationalities: the majority was born in Switzerland, but also three Italians, one Spanish, one German, one Swedish, two Japanese, and one Canadian participated. The professional's education background included: practical banking training completed by theoretical courses (5 participants), commercial diploma (8 participants), and university graduates in political economy, economics, mathematics, engineering and econometrics. The average length of service in the same bank was 11 years for women and 9 years for men. Table I summarizes areas of responsibility of participants. The majority of participants are asset and relationship managers. The 20 professionals that fall into this category manage assets from 50 to 250 millions CHF. Dependent on the agreement with the client this work can consist in either managing a portfolio under a management mandate (i.e. for a given 'risk level') or deciding on investment together with the client when no mandate is given. ${ }^{3} \mathrm{~A}$ further 9 participants are financial analysts that have no direct client contact however are responsible for providing recommendations and analysis to the asset managers.

Table I: Area of responsibility of professionals

\begin{tabular}{|c|c|c|c|c|}
\hline & & Female & Male & Total \\
\hline \multirow{2}{*}{ Asset and relationship managers } & senior & 5 & 13 & 18 \\
\hline & junior & 2 & & 2 \\
\hline Financial analyst and investment funds managers & & 2 & 7 & 9 \\
\hline Trader & & 1 & & 1 \\
\hline Chief financial officer & & 1 & & 1 \\
\hline
\end{tabular}

\footnotetext{
${ }^{3}$ According to the banks' annual report in 2008 around 815 million CHF were held in funds under own management and about 1462 million CHF were under portfolio management mandate.
} 
Even though the order of the two sessions varied for professionals and students, the same protocol was applied for each of the two sessions. At the beginning of the questionnaire session, participants were informed that they would have to fill out a number of questionnaires concerning their personality. It took participants between 40 to 60 minutes to answer all the questionnaires. At the beginning of the investment task, participants were informed that they would participate in an investment game in which they could earn points that would be converted to real money at a specified exchange rate at the end of the session. Students received $30 \mathrm{CHF}^{4}$ and professionals 60 CHF (equivalent to 3000 points) as initial capital and were handed the money in envelopes ${ }^{5}$.

This money was the capital that could be used for investment in the two years of 15 rounds each. In each round, participants made decisions concerning 100 points from their initial capital. Points had to be distributed between two projects: a safe project and a risky project. In one of the two years the risky project had an expected value higher than the safe project in the other year the value was lower. Specifically in 'good' years investment in the risky project resulted in gains of 2.5 times the investment with probability $p=1 / 3$ and in bad years the probability of gains was $p=1 / 4$. Probabilities and returns for the first year were described in the instructions and it was made clear that more information would follow after year one. After finishing the fifteen rounds of the first year a short note informed participants about the new probability of gains from the risky project. It was made clear that besides this nothing had changed in the game. A short questionnaire after the initial instructions verified that participants did understand the information given. To control for order effects the order of 'good' and 'bad' years was counterbalanced across participants.

After participants had read the instructions, they answered a number of control questions and were invited to address any remaining questions to the experimenter. To keep feedback comparable across treatment, outcomes from investment were predetermined by random sequences that were equally distributed across treatments.

\footnotetext{
${ }_{5}^{4}$ At time of study $30 \mathrm{CHF}$ equaled approximately $\$ 25$.

${ }^{5}$ Doubling the earnings for finance professionals was based on discussions with our contact from human resources from the implied bank. Note that in a similar study professional traders earned about $\$ 30$ for participation (Haigh and List, 2005).
} 


\subsection{Predictions and Hypothesis}

Our first question will focus on whether the probability of the risky project will indeed influence investment amounts. Given that the expected value of the risky project is larger than safe project for good markets, and lower than the safe project for bad markets, we expect a risk neutral decision maker to invest fully in good markets and not to invest in bad markets. Risk aversion might lead to intermediate investment for good markets, but certainly investment should be higher for good markets than for bad markets. Our first hypothesis is therefore:

HYPOTHESIS 1: Investment is on average and for each subject higher for good market conditions than for bad market conditions.

Predictions could differ if risk aversion depends on how earnings are evaluated with respect to some reference point (Kahneman and Tversky, 1979). In such cases, a within-subject comparison for investment in different markets might be problematic, since risk taking behavior will always be influenced by previous outcomes and probabilities. Past studies have already confirmed that previous outcomes will influence future choices. Examples are the "hot hand effect" and "gamblers fallacy" (Tversky and Kahneman, 1971; Croson and Sundali, 2005). However, it is not known whether these effects are influenced by the specific probabilities of winning. We will thus investigate the presence of these effects and their relative strength given the two probability conditions. If probabilities are reflected in the gamblers fallacy (which has been labeled as the "law of small numbers"), we expect this effect to be influenced by market conditions and to be stronger for bad markets. Specifically if the probability of loosing is high, observing a gain will in case of the gamblers fallacy lead to the belief that the next round will more likely be a loosing round.

HYPOTHESIS 2: If the gambler's fallacy occurs, the effect should be stronger for bad markets than for good markets.

Our third question concerns whether professionals show significantly different trading strategies than students. If we observe differences, we will explore whether these are due to different personality profiles or due to experience and training specific to professionals. As previous research has suggested (Sjöberg and Engelberg, 2009), professionals in the financial industry 
tend to be a self-selected sample characterized by certain personality traits enabling them to take high risks. Thus, we expect professionals to be less anxious and more optimistic than our student population.

HYPOTHESIS 3: Professionals show a personality profile different from students. Namely they are characterized by less anxiety and more optimism.

We further predict that personality will influence investment behavior for the two different markets. Specifically optimism will be related to more risk taking, leading to higher investment for both market conditions. Trait anxiety can be related to the anticipation of anxiety in which case economic models of anticipatory emotions predict less risk taking ( $\mathrm{Wu}, 1999$; Caplin and Leahy, 2001). However studies on gamblers have shown a link between high trait anxiety and an urge to gamble (Zangeneh et al., 2008). Thus, we might expect anxiety to have either a negative or positive impact on risk taking. Impulsivity implies more impulsive reactions to outcomes. This can be either a tendency to give in to risk aversion once small gains are made or a tendency to continue gambling once losses are encountered (Lynam and Miller, 2004). Impulsivity might therefore show a very different impact for good or for bad markets. For good markets it might decrease risk taking while for bad markets it might increase risk taken. Finally, we also include Openness to Experience, to allow for a personality trait related to curiosity and novel approaches to new situations. Generally research focuses on why stock investment is 'not high enough' given the long term observation that returns from stocks are on average higher than returns from bonds (e.g. Mehra and Prescott, 1985). This leads to a general tendency to consider risk taking as advantageous, and especially so if it is presented as an investment setting. Consequently, unfavorable probabilities might be ignored. We predict that participants high in openness will be more likely to adapt to a novel situation and be more likely to react appropriately to the low probability of winning in the bad market.

HYPOTHESIS 4: We expect investment behavior to be influenced by personality. The influence on risk taking will differ between good and bad market years.

\section{Results}

We now come to a presentation of the results. In the next section, we will give general descriptive 


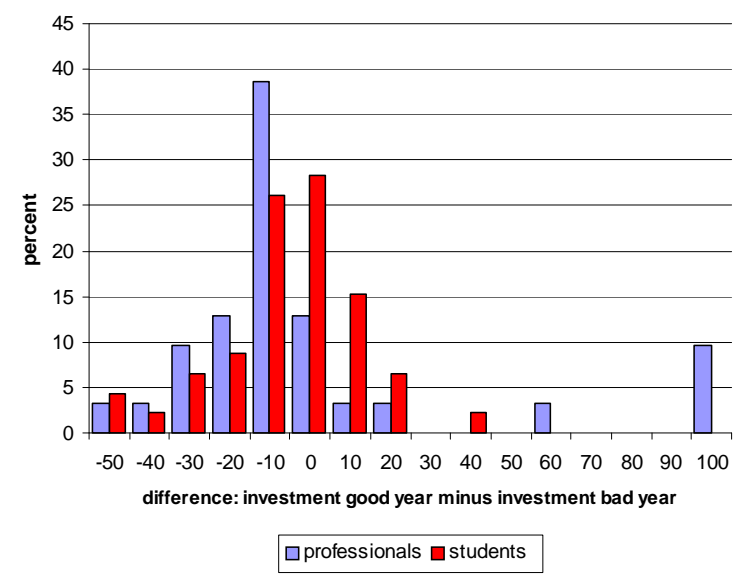

Figure 2: Histogram of investment difference between good and bad years for professionals and students.

statistics concerning investment behavior across the different treatments. In sections 2.2 and 2.3, we will then investigate the impact of markets, experience, and personality on investment choices.

\subsection{General descriptive statistics}

Overall investment over treatments and rounds is at $42.1 \%$, with average investment in good years at $42.9 \%$ and in bad years at $40.6 \%$. Investment in good years is thus slightly higher, however this difference is not significant (Wilcoxon sign-rank test, $\mathrm{p}=0.978$ ). Moreover, this difference is mainly due to the professional's behavior. While professionals invested $45.4 \%$ in good markets and $39.6 \%$ in bad markets (Wilcoxon sign-rank test, $\mathrm{p}=0.616$ ), students had an average investment of $41 \%$ in both market conditions. The difference for professionals is mainly due to four out of 31 participants (i.e. $13 \%$ ) who invest on average at least 60 units more in good years than in bad years (see also Figure 2). Ignoring these few observations, we observe for professionals a slight bias to lower investment for good than bad years. ${ }^{6}$ Overall, our results show that investment is largely unaffected by probabilities of winning.

\footnotetext{
${ }^{6}$ Excluding the four participants investing at least 60 units more in good markets we observe for professionals a mean of -6.54 while students show a mean of -0.09 .
} 


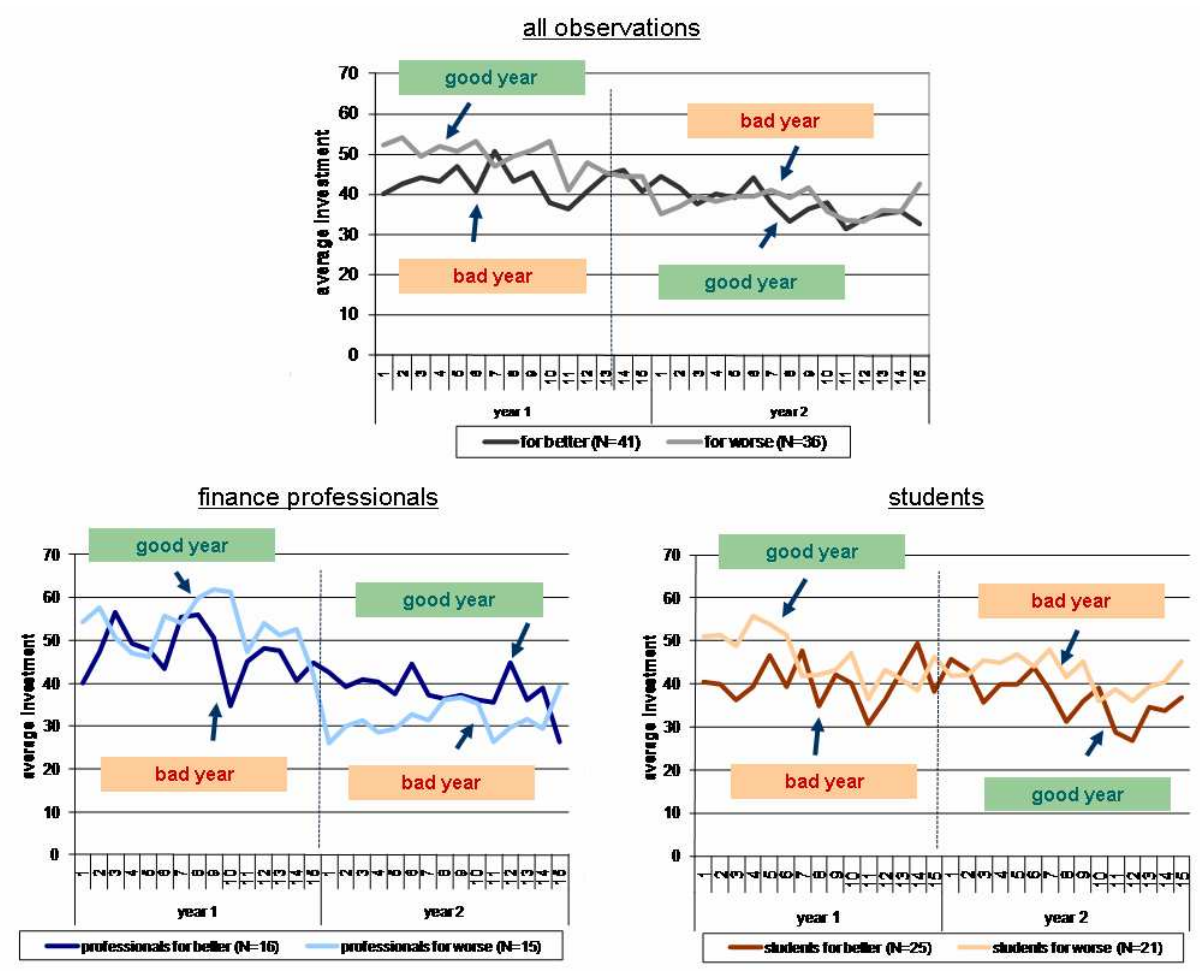

Figure 3: Investment over rounds and years. Top panel: all observations. Bottom left: professionals. Bottom right: students.

This result is further confirmed by investment over rounds in each year. In Figure 3, we present the investment timeline for investors who first face a good and then a bad year ("for worse") and for investors who first face a bad and then a good year ("for better"). It is striking that we do not observe a strong difference for the treatment order. Specifically, although we observe slightly higher investments during the first years for investors in a good market, investments are very similar in the second year. This tendency is stronger for professionals (bottom, left panel) than for students. ${ }^{7}$ Students show almost no difference in investment for the two years. For professionals, we observe that the order of the years matters. Overall, we observe a clearly negative time trend over years. Investment in the first year is significantly higher than investment in the second year, independent of whether a good year was followed by a bad year or the other way round. Specifically, investment decreased from $43.0 \%$ to $37.4 \%$ when markets changed for better, and investment decreased from $49.1 \%$ to $37.9 \%$ when markets changed for worse. In both cases this

\footnotetext{
${ }^{7}$ The clear difference for finance professionals is due to the fact that the previously identified 4 participants that invested at least 60 points more in good versus bad markets were in the treatment 'for worse'.
} 
difference is significant (Wilcoxon signed-rank test: "for better" $p=0.027$; "for worse" $p=$ 0.064).

RESULT 1: Independent of training, investment is similar for good and for bad market conditions.

\subsection{Investment dynamics}

To investigate investment strategies based on previous outcomes we will examine behavioral dynamics over rounds and years. In Error! Reference source not found.Table II (columns (1) and (3)) we present results from a random effects tobit regression of investment at time $t$ on previous outcomes and relative earnings ${ }^{8}$ as well as dummies for student, year (and period), and gender. We show separate regression results for investment made under bad market conditions (column 1) and good market conditions (column 3). As earlier results have shown (cf. Hopfensitz, 2009), both previous gains (i.e. having won in the previous rounds) and relative earnings (i.e. deviations from a reference point) have a significant impact on investment. We observe evidence of the gambler's fallacy, namely that investment is reduced after a lucky round, as well as a general reduction in investment for higher levels of earnings. These results are also confirmed by answers to an open-ended question concerning the participants' investment strategy (see Appendix C). A large amount of participants refers in this to the idea of 'avoiding' or to 'equaling out' losses and to reactive strategies based on outcomes from earlier rounds. As predicted the gamblers fallacy is more pronounced for bad than for good market conditions. Further as observed in section 3.1 investment in the second year is generally lower. However across the periods of each year we observe a general positive time trend. We observe no significant difference between students and finance professionals, however a clear gender effect. Women take less risk in both market environments, a result consistent with the literature (Croson and Gneezy, 2009). Note that all of these effects are quite similar for good and bad market conditions.

RESULT 2: Results from a random effects tobit regression show that winning and relative earnings have a negative impact on investment for both market conditions. We observe no difference for

\footnotetext{
${ }^{8}$ Relative earnings at time $t$ are the aggregate earnings of all previous time periods. Counting a positive outcome for an investment of level $x$ as a gain of $2.5^{*} x$ and a negative outcome as a loss of $x$. Thus relative earnings can be seen as a deviation of the current budget level from a references point. The reference point is taken as possible earnings if no investment would have been made so far.
} 
students and professionals however a clear gender effect.

Table II: Random effects tobit regression of investment for good and bad market conditions

\begin{tabular}{|c|c|c|c|c|}
\hline & \multicolumn{2}{|c|}{ "bad" market } & \multicolumn{2}{|c|}{ "good" market } \\
\hline & (1) & (2) & (3) & (4) \\
\hline & investment & investment & investment & investment \\
\hline \multirow[t]{2}{*}{ win previous round (dummy) } & -6.951 & -7.462 & -4.571 & -3.866 \\
\hline & $(2.54)^{* *}$ & $(2.75)^{* * *}$ & $(1.73)^{*}$ & $(1.49)$ \\
\hline \multirow[t]{2}{*}{ total relative earnings at time $t$} & -0.070 & -0.060 & -0.095 & -0.103 \\
\hline & $(6.42)^{* * *}$ & $(5.51)^{* * *}$ & $(9.51)^{* * *}$ & $(11.05)^{* * *}$ \\
\hline \multirow[t]{2}{*}{ period (1 to 15$)$} & 0.717 & 0.755 & 1.113 & 1.208 \\
\hline & $(2.78)^{* * *}$ & $(2.96)^{* * *}$ & $(3.73)^{* * * *}$ & $(4.14)^{* * * *}$ \\
\hline \multirow[t]{2}{*}{ student (dummy) } & -0.663 & 15.475 & -4.170 & 9.266 \\
\hline & $(0.15)$ & $(3.53)^{* * *}$ & $(0.78)$ & $(2.34)^{* * *}$ \\
\hline \multirow[t]{2}{*}{ year $(1$ or 2$)$} & -8.766 & -14.617 & -29.179 & -14.576 \\
\hline & $(2.35)^{* *}$ & $(4.20)^{* * *}$ & $(6.04)^{* * *}$ & $(4.40) * * *$ \\
\hline \multirow[t]{2}{*}{ sex ( 1 male; 2 female) } & -15.996 & -6.220 & -17.180 & -21.298 \\
\hline & $(3.96)^{* * * *}$ & $(1.48)$ & $(3.28) * * *$ & $(5.58) * * *$ \\
\hline \multirow[t]{2}{*}{ optimism (LOT) } & & 23.563 & & 7.343 \\
\hline & & $(5.92) * * *$ & & $(1.70)^{*}$ \\
\hline \multirow[t]{2}{*}{ anxiety (STAI) } & & 22.084 & & 18.687 \\
\hline & & $(4.21)^{* * *}$ & & $(3.04) * * *$ \\
\hline \multirow[t]{2}{*}{ impulsivity (UPPS) } & & 47.264 & & -15.193 \\
\hline & & $(5.42) * * *$ & & $(1.67)^{*}$ \\
\hline \multirow[t]{2}{*}{ openness (Big Five) } & & -9.529 & & 8.800 \\
\hline & & $(2.31)^{* *}$ & & $(2.34)^{* *}$ \\
\hline \multirow[t]{2}{*}{ Constant } & 69.848 & -147.768 & 123.983 & 30.156 \\
\hline & $(7.08) * * *$ & $(5.55) * * *$ & $(12.36)^{* * *}$ & $(0.95)$ \\
\hline Observations & 1155 & 1155 & 1155 & 1155 \\
\hline Number of id & 77 & 77 & 77 & 77 \\
\hline Wald Chi 2 & 100.62 & 186.72 & 178.87 & 199.33 \\
\hline \multicolumn{5}{|c|}{ Absolute value of z statistics in parentheses } \\
\hline * significant at $10 \% ; * *$ signific & at $5 \% ; * * * s i$ & iificant at $1 \%$ & & \\
\hline
\end{tabular}

\subsection{Personality and investment}

In addition to reactions to outcomes we expect a large heterogeneity of risk taking across participants. To understand which individual factors influence investment decisions we will now turn to an analysis of the personality profile of participants. Since professionals in the financial 
sector might be self-selected based on their personality we will first compare personality traits between students and finance professionals. We will then use personality characteristics to explain investment behavior in the two markets.

Table III: Overview of personality variables for students and professionals.

\begin{tabular}{lrrrrr}
\hline & professional $(\mathrm{N}=31)$ & \multicolumn{2}{c}{ student $(\mathrm{N}=46)$} & $\begin{array}{r}\text { Wilcoxon } \\
\end{array}$ \\
& Mean & Std. Dev. & Mean & Std. Dev. & rank sum test \\
\hline optimism (LOT) & 3.75 & 0.46 & 3.46 & 0.62 & $\mathrm{p}=0.052$ \\
anxiety (STAI) & 1.73 & 0.33 & 2.21 & 0.49 & $\mathrm{p}=0.000$ \\
impulsivity (UPPS) & 2.22 & 0.23 & 2.29 & 0.21 & $\mathrm{p}=0.271$ \\
openness (Big Five) & 3.72 & 0.45 & 3.72 & 0.53 & $\mathrm{p}=0.859$ \\
\hline
\end{tabular}

We first compared personality scores for professionals and students. Table III gives an overview of mean ratings for optimism, anxiety, impulsivity and openness. Professionals score higher on optimism and lower on anxiety compared to students (Wilcoxon rank sum test, $\mathrm{p}<0.052$ ). We observe no other significant differences. The results concerning optimism and anxiety reflect the common perception of personality characteristics of finance professionals. It might seem surprising that we do not find any difference concerning impulsivity, however it should be noted that professionals score significantly lower on one of the impulsivity subscales: namely "lack of perseverance" (professionals: 1.82 ; students: $2.08 ; \mathrm{p}=0.008$ ).

Given these differences, we add personality measures to the tobit regressions (Table II, columns (2) and (4)). ${ }^{9}$ The effect of winning previously, relative earnings, and period in the year remain mostly unchanged. However, the student dummy now shows a positive coefficient. In addition, the gender effects is no longer significant for bad markets. Thus, the effect of being a student and female seem to be related to the included personality variables.

Overall, we observe that personality variables have a significant impact on investment behavior. Optimism and anxiety are significant for both market conditions. Optimism generally leads to

\footnotetext{
${ }^{9}$ To control for the robustness of our results we also ran regressions excluding the four finance professionals that were close to maximizing the expected value in both market conditions. Our qualitative results concerning optimism, anxiety and openness are unchanged (solely openness is no longer significant in good markets). However the fact that these participants were able to stay with a predetermined strategy and not to react to outcomes already indicates that they were not very impulsive. Consequently the significant coefficient for impulsivity disappears when these participants are excluded.
} 
higher investment, and especially so under bad market conditions. Given that participants lose money (on average) under bad market conditions, optimism leads to a stronger effect in bad than in good markets. In good markets optimism is less influential because investment is in itself advantageous (on average). Anxiety has a similar effect. What might be surprising is that anxiety is positively related with investment. Thus, trait anxiety is related to taking more risk, as predicted by the literature on gambling (Zangeneh et al, 2008) and not to reduced risk taking as has been suggested by economic models (Wu, 1999; Caplin and Leahy, 2001) ${ }^{10}$.

Impulsivity shows a differential effect on behavior for good and bad markets. While impulsivity leads (on average) to more investment for bad markets, it leads (on average) to less investment for good markets. Since investment is favorable in good markets and unfavorable in bad markets, this implies that high levels of impulsivity will lead to unfavorable investment decisions and therefore losses in both market conditions. That impulsivity might have different effects given the market conditions is important given the previous observation that sensation seeking will increase trading in general (Grinblatt and Keloharju, 2009).

Finally, we observe that openness reduces investment in bad markets. ${ }^{11}$ People high in 'openness to experience' have a stronger preference for novelty, variety, and complexity (McCrae, 1996) and to be less conventional and think more deeply about new information than those low in 'openness to experience' (McCrae, 1987). Therefore, those high in this trait may have been more attentive to the probabilities presented and considered the implications of these probabilities. We conclude the Openness to Experience might favor investment behaviors in changing markets, because new information is more likely to be integrated and used in decision-making.

RESULT 3: We observe significant differences in the personality profile of professionals and students. Moreover, personality variables significantly influence investment behavior and the specific impact depends on the market condition.

\footnotetext{
${ }^{10}$ Note that also earlier economic experiments did fail to observe reduced risk taking for participants high on trait anxiety (Hopfensitz and van Winden, 2008).

${ }^{11}$ This result is further supported by a significant correlation between mean investment in the bad market case and openness (corr. coef $=-0.306, \mathrm{p}=0.008$ ).
} 


\section{Summary and conclusions}

Real markets are variable, and risk taking and investment in stock will be more advantageous in some periods rather than others. We wanted to determine if and how investors would adapt to changing market conditions, and to examine if professional experience or personality could help predict the capacity to adapt. Surprisingly, professional investors did not show more adaptive responses to changing markets, than students.

Personality plays a role in risk taking and adaptation. Openness to experience can help investors to take into account new information to challenge dominant responses to risk taking. Being open to variable market conditions and alternative investment strategies can be an asset, and is a capacity that can be both selected and trained. Impulsivity, on the other hand, is unfavorable in all accounts. This was also found in an examination of long term investment strategies for clients in regards to their retirement investment (Ameriks et al., 2009). Thus, impulsivity and sensation seeking, which often characterize trader personality (Sjöberg and Engelberg, 2009), may have to be reconsidered. Finally, both optimism and anxiety have more complex relationships to risk taking and adaptation than previously thought, and the widely held belief that optimism is a positive and anxiety a negative trait for investment may prove to be false. Moderated levels of anxiety have indeed been shown to be an asset for long term investment decision-making (Ameriks et al., 2009). Given the current financial crisis, and the repeated demonstration that many financial institutions collectively take unreasonable levels of risk, a discussion on how professionals are selected and trained may warrant further exploration and discussions. 


\section{References:}

Ameriks, J., T. Wranik and P. Salovey (2009). Emotional intelligence, personality, impulsivity, and investor behavior. CFA Institute Research Foundation Publications.

Bechara, A., H. Damasio, D. Tranel and A. Damasio (1997). Deciding advantageously before knowing the advantageous strategy. Science. 275:1293-1294.

Bellemare, C., M. Krause, S. Kroeger and C. Zhang (2005). Myopic loss aversion: information feedback vs. investment flexibility. Economics Letters. 87(3):319-324.

Brandstaetter, H. (1997). Becoming an entrepreneur -- A question of personality structure? Journal of Economic Psychology. 18(2-3): 157-177.

Burns, P. (1985). Experience in decision making: A comparison of students and businessmen in a simulated progressive auction, in V. L. Smith, ed. Research in Experimental Economics (JAI Press, Greenwich).

Caplin, A., and J. Leahy (2001). Psychological expected utility theory and anticipatory feelings. The Quarterly Journal of Economics, 116(1):55-79.

Carver, C. and M. Scheier (2001). Optimism, pessimism, and self-regulation. In Chang and Edward (eds.). Optimism \& pessimism: Implications for theory, research, and practice. Washington: American Psychological Association.

Croson, R. and Gneezy, U. (2009). Gender differences in preferences. Journal of Economic Literature. 47(2): 448-474.

Croson, R. and J. Sundali (2005). The Gambler's Fallacy and the Hot Hand: Empirical Data from Casinos. The Journal of Risk and Uncertainty. 30:195-209.

Gneezy, U. and J. Potters (1997). An experiment on risk taking and evaluation periods. The Quarterly Journal of Economics. 112(2):631-645.

Grinblatt, M. and M. Keloharju (2009). Sensation Seeking, Overconfidence, and Trading Activity. Journal of Finance. 64(2): 549-578.

Haigh, M. and J. List, 2005, Do professional traders exhibit myopic loss aversion? An experimental analysis. The Journal of Finance, 60(1):523-534. 
Holt, C., and S. K. Laury, 2002, Risk Aversion and Incentive Effect, The American Economic Review, 92(5):1644-1655.

Hopfensitz, A. (2009). Previous outcomes and reference dependence: A meta study of repeated investment tasks with and without restricted feedback. MPRA working paper nr. 16096

Hopfensitz, A. and van Winden, F. (2008). Dynamic Choice, Independence, and Emotions. Theory and Decision, 64: 249-300.

Hopfensitz, A. and T. Wranik (2008). Psychological and Environmental Determinants of Myopic Loss Aversion. NETSPAR discussion paper. nr. 2008-013

John, O. P. and S. Srivastava (1999). The Big Five Trait Taxonomy: History, Measurement, and Theoretical Perspectives. In L.A. Pervin and O.P. John (eds.), Handbook of Personality: Theory and Research. New York: Guilford Press.

Kahneman, D., and A. Tversky (1979). Prospect theory: An analysis of decision under risk. Econometrica. 47:263-291.

Lo, A.W, D.V. Repin and B. N. Steenbarger (2005). Fear and Greed in Financial Markets: A Clinical Study of Day-Traders. The American Economic Review. 95(2): 352-359.

Lynam, D. R. and J. D. Miller (2004). Personality pathways to impulsive behavior and their relation to deviance: Results from three samples. Journal of Quantitative Criminology, 20: 319341.

McCrae, R. R. (1987). Creativity, divergent thinking, and Openness to Experience. Journal of Personality and Social Psychology, 52: 1258-1265.

McCrae, R. R. (1996). Social consequences of experiential openness. Psychological Bulletin, 120: 323-337.

Mehra, R. and E. C. Prescott (1985). The equity premium: A puzzle. Journal of Monetary Economics, 15:145-161.

Potters, J. and F. van Winden (2000). Professionals and students in a lobbying experiment: Professional rules of conduct and subject surrogacy. Journal of Economic Behavior \& Organization, 43(4): 499-522. 
Shiv, B., G. Loewenstein and A. Bechara (2005a). The dark side of emotion in decision-making: When individuals with decreased emotional reactions make more advantageous decisions. Cognitive Brain Research. 23:85-92.

Shiv, B., G. Loewenstein, A. Bechara, H. Damasio and A. Damasio (2005b). Investment Behavior and the Negative Side of Emotions. Psychological Science. 16(6):435-439.

Sjöberg, L. and E. Engelberg (2009). Attitudes to economic risk taking, sensation seeking and values of business students specializing in finance. Journal of Behavioral Finance, 10: 33-43.

Spielberger, C. D. (1972). Anxiety as an emotional state. In Anxiety: Current trends in theory and research, 1. New York: Academic Press.

Thaler, R., A. Tversky, D. Kahneman and A. Schwartz (1997). The effect of myopia and loss aversion on risk taking: An experimental test. The Quarterly Journal of Economics. 112(2):647661.

Tversky, A. and D. Kahneman (1971). Belief in the law of small numbers. Psychological Bulletin, 76, 105-110.

Whiteside, S. P. and D.R. Lynam (2001). The Five Factor Model and Impulsivity: Using a Structural Model of Personality to Understand Impulsivity. Personality and Individual Differences, 30: 669-689.

Wu, G., (1999). Anxiety and Decision Making with Delayed Resolution of Uncertainty, Theory and Decision, 46(2):159-199.

Zangeneh, M., A. Grunfeld and S. Koenig (2008). Individual factors in the development and maintenance of problem gambling. In M. Zangeneh, A. Blaszczynski and E. Turner (eds.). In the pursuit of winning: Problem gambling theory, research and treatment. New York: Springer Science + Business Media. 


\section{Appendix A: Instructions}

\section{General instructions [for year 1 - good market; values for bad market in brackets; values} for finance professionals in parenthesis]

Welcome: you are about to take part in a decision making experiment, in which you can earn real money. The experiment has 2 parts, which we will call years. The amount of money you can earn will depend on the decisions you make.

Dependent on your decisions, you can earn a significant amount of money.

During the experiment your earnings will be calculated in Unige Francs (UGF). At the end of the two years, these UGF will be converted into CHF and your earnings will be paid out to you in $\mathrm{CHF}$ using the following exchange rate:

\section{$100 \mathrm{UGF}=1 \mathrm{CHF}(\mathbf{2} \mathbf{C H F})$}

At the beginning of the experiment you will receive from us $30 \mathrm{CHF}(60 \mathrm{CHF})$, which $=3000$ UGF. This is your capital stock. You will have access to 1500 UGF of your capital stock at the beginning of each year. You can decide to either keep these UGF or to invest them in the experiment and try and earn more money. The details of this investment procedure will be explained to you below. At the end of the experiment we will pay you any earnings that you accumulated from the two years in addition to your 3000 UGF capital stock. If you lose money during the experiment, you will have to pay us back the losses from your capital stock at the end of the experiment.

During the experiment we will also ask you to answer a number of questions. These questions concern what you think and how you feel.

There are no right or wrong answers. You need to follow the decision strategy that feels right to you and to make those choices that come natural and that seem like the best choices for you. In addition, you should report those evaluations and emotions that are closest to your real thoughts and feelings. All answers are completely anonymous and confidential.

\section{General instructions}

During this experiment you will have to make investment decisions for 15 rounds in two investment years. This means that you will be making decisions for 30 rounds in total. In each of these rounds, you can invest 100 UGF from your capital stock of 3000 UGF.

We will now explain to you your options in year 1. After the 15 rounds of year 1 we will explain to you the situation in the second year.

\section{$\underline{\text { Instructions for year } 1}$}

In year 1 you will have to make investment decisions for 15 rounds. In each of these rounds, you can invest 100 UGF from your capital stock. Each round you have to decide how you want to split these 100 UGF over two investment options. 
We will call the two options: option A and option B.

Option A: In this option you will neither gain nor lose money. In other words, will always keep the number of UGF you put into option A.

Option B: The outcome from this option will be determined at the end of each round. In particular, we will pick one random number between 1 and 100. This is equivalent to picking a ball from an urn.

Imagine an urn with 100 balls in it, 33 [25] of these balls are orange, 67 [75] of these balls are blue.

- If the ball that is picked is orange (that is in $1 / 3$ [1/4] of the cases) the UGF you placed in this option will be multiplied by 2.5 . You will then receive 2.5 times the number of UGF you put into option $\mathrm{B}$, in addition to the number of UGF you originally place into this option.

- If the ball that is picked is blue (that is in $2 / 3$ [3/4] of the cases) you will lose the number of UGF you put into option B.

Note: For all fifteen rounds of year 1 we will always use the same urn. The number of orange and blue balls in this urn represents the market conditions of year 1.

\section{Example}

Imagine that in one round, you decide to split your 100 UGF by placing 50 UGF into option A and 50 UGF into option B.

If the randomly picked ball is orange (i.e. if the random number is smaller or equal to 33 [25]), you will receive $2.5 * 50=125$, in addition to your $100 \mathrm{UGF}$ for that round. Your capital stock will therefore increase by 125 UGF.

If the randomly picked ball is blue (i.e. if the random number is larger than 33 [25]), you will lose the 50 UGF you put in option B. Your capital stock will therefore decrease by 50 UGF.

\section{Summary for year 1}

- Year 1 is made up of 15 investment rounds.

- In each round, you can decide how to split 100 UGF of your capital stock between two options.

- At the end of each round we will pick a random number between 1 and 100.

- If the randomly picked ball is orange (i.e. if the random number is smaller or equal to 33 [25]) your earnings will be: $100 \mathrm{UGF}+2.5 *$ the number of UGF you placed into option B

- If the randomly picked ball is blue (i.e. if the random number is larger than 33 [25]) your earnings will be: $100 \mathrm{UGF}$ - the number of UGF you placed into option B 


\section{Appendix B: Recruitment letter for professionals}

Dear all,

Today I need your collaboration to help me with the research that is part of my master thesis in human resources, which I have been following by now for 18 months.

Do you know 'behavioral finance'? This is the study of investors' behavior in financial markets from a 'psychological' perspective or as stated by the American economist Richard Thaler, following an open minded approach.

Individual differences (personality, training ...) play an important role in everyday decisions and studies have shown that they are also important in financial investment decisions.

[...] I would like to investigate with an experimental study the importance of personality differences for financial decisions. To conduct this research your professional help will be indispensable. You just have to give me 2 and a half hour of your time [...].

The study will be conducted in small groups: each of you will work individually and completely anonymous (not only will you be protected by our professional vow of silence but we will also sign an individual declaration with each of you promising complete confidentiality). It is neither an exam nor an evaluation and our bank will only be informed about the aggregate results from this study, thus this research will be fully anonymous.

I am sure that this study will interest you ... and it will even hold some small and nice surprises. $[\ldots]$ 


\section{Appendix C: self reported investment strategies (translated from the French)}

\begin{tabular}{|c|c|c|c|c|}
\hline \multicolumn{5}{|c|}{$\begin{array}{rr}\text { finance professionals } \\
\end{array}$} \\
\hline \multicolumn{2}{|c|}{ invest by year } & \multicolumn{2}{|c|}{ invest by prob. } & \multirow[b]{2}{*}{ self reported strategy } \\
\hline 1 & 2 & good & bad & \\
\hline 0,00 & 0,00 & 0,00 & 0,00 & no gambles \\
\hline 0,00 & 0,00 & 0,00 & 0,00 & $\begin{array}{l}\text { Calculate the expected gains and choose the option where it is higher (but, thinking } \\
\text { about it, I fear to have miscalculated for the first part...) }\end{array}$ \\
\hline 11,33 & 0,60 & 0,60 & 11,33 & \\
\hline 15,20 & 2,73 & 2,73 & 15,20 & \\
\hline 15,00 & 7,00 & 15,00 & 7,00 & conservation of capital \\
\hline 32,00 & 17,33 & 17,33 & 32,00 & $\begin{array}{l}\text { I started very prudent thus } 2 / 3 \text { option } A \text { and } 1 / 3 \text { option } B \text {, if during one parte the first } \\
\text { draws were blue balls I increased option B, if however the first draws were positive I } \\
\text { decreased the gamble in the latter and sometimes I put } 100 \% \text { in option A. Also note } \\
\text { that in the second year I increased a bit the bets due to the number of orange balls } \\
\text { with respect to blue balls. }\end{array}$ \\
\hline 20,00 & 20,00 & 20,00 & 20,00 & conservation of capital, by placing $80 \%$ on the $100 \%$ safe, and by taking risk with $20 \%$. \\
\hline 20,67 & 2,00 & 20,67 & 2,00 & $\begin{array}{l}\text { The probability of winning was very much to my disfavor, thus to win you should not } \\
\text { gamble. }\end{array}$ \\
\hline 26,67 & 20,67 & 20,67 & 26,67 & \\
\hline 25,33 & 18,80 & 25,33 & 18,80 & All depends on the profile, the characteristics of the person, the global assets etc. \\
\hline 31,67 & 26,00 & 26,00 & 31,67 & $\begin{array}{l}\text { Do such that you take not too much risk concerning the investment and when the } \\
\text { markets become too volatile try to keep as much capital as possible. }\end{array}$ \\
\hline 25,33 & 30,00 & 30,00 & 25,33 & Distribution of risk, protection of capital and growth of portfolio. \\
\hline 63,33 & 33,53 & 33,53 & 63,33 & $\begin{array}{l}\text { After multiple identical tries } 50 / 50 \text { or } 67 / 33 \text {, I believed that there would necessarily } \\
\text { be a winning ball. Sometimes luck made things well. }\end{array}$ \\
\hline 80,00 & 34,00 & 34,00 & 80,00 & $\begin{array}{l}\text { During the second year I tried to bet on each option as a function of its expected } \\
\text { gains. }\end{array}$ \\
\hline 53,33 & 35,60 & 35,60 & 53,33 & \\
\hline 48,33 & 48,33 & 48,33 & 48,33 & \\
\hline 43,33 & 48,67 & 48,67 & 43,33 & Conservation of capital \\
\hline 54,00 & 54,00 & 54,00 & 54,00 & $\begin{array}{l}\text { Invest at the beginning an amount a bit higher or equal in option } A \text {. Then, in the case } \\
\text { of gain, reduce option B in the favor of option A, in case of a loss, increase option B } \\
\text { by reducing option } A \text {. }\end{array}$ \\
\hline 54,67 & 77,33 & 54,67 & 77,33 & \\
\hline 55,33 & 34,67 & 55,33 & 34,67 & Intermediate amount of risk. \\
\hline 58,67 & 90,00 & 58,67 & 90,00 & \\
\hline 60,00 & 61,33 & 60,00 & 61,33 & \\
\hline 63,33 & 60,00 & 60,00 & 63,33 & \\
\hline 62,67 & 90,67 & 62,67 & 90,67 & \\
\hline 74,67 & 12,00 & 74,67 & 12,00 & $\begin{array}{l}\text { Year 1: start by a small amount invested and double that amount until I win. Year 2: } \\
\text { Worry of keeping the capital, less gambling, aiming better and less big, not to get } \\
\text { under amount initially invested in year } 1 . \text { I never play more than what I have already } \\
\text { gained }\end{array}$ \\
\hline 76,00 & 80,00 & 76,00 & 80,00 & I took a maximum of risk. \\
\hline 86,67 & 80,00 & 80,00 & 86,67 & \\
\hline 93,33 & 0,00 & 93,33 & 0,00 & $A=0 B=100$ in experiment $1 ; A=100 B=0$ in experiment 2 \\
\hline 100,00 & 0,00 & 100,00 & 0,00 & $\begin{array}{l}\text { The proposition was preferable in the long term, thus I bet all onto B. } 2 \text {. The } \\
\text { proposition was on the long term unfavorable, thus I bet all on } A \text {. }\end{array}$ \\
\hline 100,00 & 0,00 & 100,00 & 0,00 & $100 \%$ risk at the beginning then $0 \%$, because probability changed from $33 \%$ to $25 \%$. \\
\hline 100,00 & 100,00 & 100,00 & 100,00 & \\
\hline
\end{tabular}


students

\begin{tabular}{rrrrl}
\hline \multicolumn{2}{c}{ invest by year } & \multicolumn{3}{c}{ invest by prob. } \\
$\mathbf{1}$ & $\mathbf{2}$ & good & bad & self reported strategy \\
\hline 0,00 & 0,00 & 0,00 & 0,00 & Not invest anything, thus no risk of losing money. \\
\hline 0,00 & 0,00 & 0,00 & 0,00 & \\
\hline 0,00 & 0,00 & 0,00 & 0,00 & \\
\hline 0,00 & 3,33 & 3,33 & 0,00 & Not invest to keep my initial capital but I gave in to the temptation in one round \\
\hline 36,33 & 5,20 & 5,20 & 36,33 & \\
\hline 11,33 & 5,87 & 5,87 & 11,33 & \\
\hline 15,00 & 9,33 & 9,33 & 15,00 & \\
\hline
\end{tabular}

It is worth to invest always a bit (10\%) in the 29 rounds, but to keep a cold head. If you do not invest you also do not gain. You only keep your assets. If you invest all, you risk to loose all. The importance is to play adequately even though you cannot control all the parameters (here: in this test the programming of winning and losing

\begin{tabular}{rrrr}
10,67 & 10,00 & 10,67 & 10,00 \\
\hline 40,00 & 10,67 & 10,67 & 40,00 \\
\hline 11,33 & 11,33 & 11,33 & 11,33 \\
\hline 40,33 & 12,33 & 12,33 & 40,33 \\
\hline 9,33 & 13,33 & 13,33 & 9,33 \\
& & & \\
14,47 & 17,33 & 17,33 & 14,47 \\
\hline 18,00 & 9,87 & 18,00 & 9,87 \\
\hline 24,33 & 14,33 & 24,33 & 14,33 \\
\hline 29,67 & 25,33 & 25,33 & 29,67 \\
\hline & & & \\
23,33 & 26,67 & 26,67 & 23,33 \\
\hline 29,33 & 25,33 & 29,33 & 25,33 \\
\hline 33,53 & 13,67 & 33,53 & 13,67 \\
\hline
\end{tabular}

rounds).

I tried to choose the logic that seemed to derive from the first year.

Not to lose my initial capital. Do better in year 2 than in year 1.

Do not risk too much and do not go below a certain amount.

Sort of a hesitant luck... sometimes I tried, but if I lost I did not invest during the

following round. Fear of losing too much....

9,87 The probabilities and the expectancies of gains for each round

Not much risk taking but by putting a bit hope on gaining a little more!

prudence

Place more when the probabilities where advantageous. Place more if I just won something, less when I just lost.

1 out of 4 cases the victory is possible (on average) - Gamble a large amount (from time to time) to try to win the most at the beginning and then once the victory was

\begin{tabular}{rrrr}
45,47 & 35,67 & 35,67 & 45,47 \\
\hline 36,33 & 21,99 & 36,33 & 21,99 \\
\hline 86,67 & 36,67 & 36,67 & 86,67 \\
\hline
\end{tabular}

obtained, just put 10 more or less since a gain is won.

\begin{tabular}{|c|c|c|c|c|}
\hline 86,67 & 36,67 & 36,67 & 86,67 & \\
\hline 21,67 & 38,33 & 38,33 & 21,67 & $\begin{array}{l}\text { With respect to the number of the round. The } 5 \text { is my lucky number (normally) thus I } \\
\text { waited for round nr. } 5 \text {. Besides at the end I put large amounts because any ways I had } \\
\text { lost a lot thus why not try to increase. }\end{array}$ \\
\hline 34,20 & 38,87 & 38,87 & 34,20 & Calculate the probabilities and 6th sense. \\
\hline 43,00 & 61,33 & 43,00 & 61,33 & Take the maximum amount of risk by limiting the losses. \\
\hline 46,00 & 45,33 & 46,00 & 45,33 & \\
\hline 50,00 & 26,67 & 50,00 & 26,67 & $\begin{array}{l}\text { At the beginning I played all, then I tried to do half half, and finally I just wanted to } \\
\text { conserve my gains. }\end{array}$ \\
\hline 50,00 & 60,00 & 50,00 & 60,00 & I tried different combinations \\
\hline 70,00 & 53,67 & 53,67 & 70,00 & \\
\hline 54,33 & 29,33 & 54,33 & 29,33 & $\begin{array}{l}\text { Count the number of times that I could win and the likely order in which the } \\
\text { computer could present the good/bad investments. }\end{array}$ \\
\hline 35,33 & 55,00 & 55,00 & 35,33 & $\begin{array}{l}\text { Equalizing the losses encountered during one round by increasing the investment in } \\
\text { the following round. }\end{array}$ \\
\hline 46,67 & 55,00 & 55,00 & 46,67 & \\
\hline 54,40 & 56,00 & 56,00 & 54,40 & $\begin{array}{l}\text { From the second year on, taking the probabilities into account: if the probability is } \\
1 / 3 \text { and I invest } 70 \text { each round, after three rounds I lose } 140 \text { but I gain } 175 \text {, thus gain } \\
\text { of } 35 \text {. However the probability of } 1 / 3 \text { rarely came true. }\end{array}$ \\
\hline 58,33 & 46,67 & 58,33 & 46,67 & \\
\hline
\end{tabular}


HOW TO ADAPT TO CHANGING MARKETS

\begin{tabular}{|c|c|c|c|c|}
\hline \multicolumn{2}{|c|}{ invest by year } & \multicolumn{2}{|c|}{ invest by prob. } & \multirow[b]{2}{*}{ self reported strategy } \\
\hline 1 & 2 & good & bad & \\
\hline 60,00 & 48,33 & 60,00 & 48,33 & trust and calmness \\
\hline 60,00 & 100,00 & 60,00 & 100,00 & \\
\hline 60,33 & 63,67 & 63,67 & 60,33 & $\begin{array}{l}\text { Very carefully, during the second year, since I had the right for three trials, I put once } \\
20 \text { in option A and } 80 \text { in option B, I checked how that went. Then, I put } 80 \text { in A and } 20 \\
\text { in B. Like that I kept a basis, then I put for example } 100 \text { in B, if I won it was good too } \\
\text { bad when I lost. }\end{array}$ \\
\hline 64,33 & 72,33 & 64,33 & 72,33 & You only won once in a part, thus once I won I didn't invest much. \\
\hline 66,67 & 46,67 & 66,67 & 46,67 & $\begin{array}{l}\text { During the first part, when I lost twice in a row } 50, \text { I tried to double how much I } \\
\text { invested in option B. During the second part, I was more reserved, because the } \\
\text { chances of winning decreased. Thus I split my investment between A and B. When I } \\
\text { lost too much in the second part, I sometimes continued dividing between A and B, } \\
\text { because else there is no interest in the game. }\end{array}$ \\
\hline 73,33 & 46,67 & 73,33 & 46,67 & \\
\hline 82,00 & 75,33 & 75,33 & 82,00 & \\
\hline 80,00 & 100,00 & 80,00 & 100,00 & \\
\hline 100,00 & 86,67 & 86,67 & 100,00 & $\begin{array}{l}\text { Try to calculate the mathematic gain, positive for the first experiment and negative } \\
\text { for the second. Then, do as Closewitz, do not change your strategy until the numbers } \\
\text { make sense... which was not the case here. }\end{array}$ \\
\hline 100,00 & 98,67 & 98,67 & 100,00 & \\
\hline 50,00 & 100,00 & 100,00 & 50,00 & \\
\hline 100,00 & 100,00 & 100,00 & 100,00 & \\
\hline
\end{tabular}

